\title{
Chapter 8 \\ Dynamic Adaptive Planning (DAP): The Case of Intelligent Speed Adaptation
}

\author{
Vincent A. W. J. Marchau, Warren E. Walker \\ and Jan-Willem G. M. van der Pas
}

\begin{abstract}
This chapter aims to close the gap between the theory and practice of Dynamic Adaptive Planning (DAP).
\end{abstract}

- It (1) presents an operationalization of DAP using experts in a workshop setting, (2) applies this operationalization to a real-world policy problem involving a traffic safety technology called intelligent speed adaptation (ISA), and (3) presents both the resulting dynamic adaptive plan and the experiences of the participating stakeholders in designing the plan.

- The workshop was conducted with stakeholders who were likely to actually participate in the planning process for ISA in the Netherlands.

- The workshop was held in a computer-supported group decision room, an interactive, computer-based environment that helps a team of decisionmakers solve problems and make choices, and began with an initial promising plan. The participants then were guided through the process of (1) assessing the strengths, weaknesses, opportunities, and threats (vulnerabilities) of the initial plan, (2) selecting the most uncertain and most important opportunities and threats, (3) defining actions aimed at increasing the robustness of the initial plan, and specifying signposts and trigger values for contingent actions to be taken over time, and (4) testing the proposed plan's performance in the face of 'wildcard scenarios.'

- In an assessment of the workshop, the participants concluded that the adaptive plan that was developed is a promising step toward the large-scale implementation of ISA in the Netherlands, and that DAP is a useful approach for dealing with deep uncertainty.

\footnotetext{
V. A. W. J. Marchau (凶)

Radboud University (RU) Nijmegen School of Management, Nijmegen, The Netherlands

e-mail: v.marchau@fm.ru.nl

W. E. Walker

Delft University of Technology, Delft, The Netherlands
}

J.-W. G. M. van der Pas

Municipality of Eindhoven, Eindhoven, The Netherlands

(C) The Author(s) 2019

V. A. W. J. Marchau et al. (eds.), Decision Making under Deep Uncertainty, https://doi.org/10.1007/978-3-030-05252-2_8 


\subsection{Introduction to the Approach}

This chapter focuses on how to bring Dynamic Adaptive Planning (DAP) into practice. Although DAP was proposed over seventeen years ago (in 2001), and many cases of its use in designing plans for various policy domains have been published (see references in Chap. 3), DAP is still considered a theoretical approach. More particularly:

1. DAP lacks examples of adaptive planning developed by policymakers or domain experts. (Until now, DAP has been carried out almost exclusively by researchers, not by real-world policymakers or domain experts.)

2. DAP lacks realistic examples of real-world policy problems. (Most cases that are published were developed as hypothetical illustrations of DAP).

3. DAP can be defined as a 'high-level concept, captured in a flowchart' (Kwakkel 2010). There is limited insight into the tools and methods needed to design an adaptive plan in practice that can be used in the various steps in the flowchart. A first indication of these is given by Swanson et al. (2010). But this overview is still very broad and needs to be operationalized.

In order to develop and test DAP, a real-world decisionmaking problem involving deep uncertainty was needed. The case we selected was the implementation of a type of innovative traffic safety technology in the Netherlands. For decades, technical systems have been available that make sure a driver cannot exceed the legal speed limit. If these 'intelligent speed adaptation' (ISA) devices would have been implemented years ago, hundreds of thousands of lives worldwide could have been saved. (For example, the Swedish National Road Administration has suggested that ISA could reduce crash injuries by $20-30 \%$ in urban areas (see https://trid.trb.org/view.aspx? $\mathrm{id}=685632$ ).) One barrier to the implementation of ISA is the uncertainty that still exists regarding the effects of (large-scale) ISA implementation (e.g., uncertainty about the acceptance of ISA, and liability in case of the system malfunctions) (van der Pas et al. 2012a). Although policymakers recognize the uncertainties that are involved in implementing ISA, their reaction is usually to initiate more research. Around 2010, Dutch policymakers developed an ISA implementation plan that was focused on implementing the appropriate ISA for the appropriate type of driver. This implementation plan was redesigned as an adaptive plan at a workshop by policymakers, domain experts, and stakeholder representatives, using DAP concepts. In this chapter, we discuss the design and results of this DAP workshop. In addition, we present an evaluation of the workshop by the participants.

\subsection{Introduction to the Case}

Every day, people in Europe and other parts of the world are confronted with the grim reality of losing loved ones due to traffic accidents. The World Health Organization 
(WHO) estimates that every year over 1.2 million people die in traffic accidents and up to 50 million suffer non-fatal injuries (WHO 2015). This means that each day over 3000 people die, which comes down to more than 2 every minute.

Research has shown that 'excessive and inappropriate speed is the number one road safety problem in many countries, often contributing as much as one third to the total number of fatal accidents' (OECD 2006). Speeding not only influences the risk of getting involved in a traffic accident, it also affects the outcomes of an accident. For the Netherlands, it has been estimated that if all motorists were to comply with the legal speed limit using ISA, it would reduce the number of accidents resulting in injury by $25-30 \%$ (Oei 2001).

To address speeding behavior, a wide range of policy alternatives have been considered in the past. These measures (speed management measures) are often categorized using the three E's: engineering (related to both vehicle and infrastructure), education, and enforcement. Examples of infrastructure engineering to reduce speeding are speed bumps and roundabouts. Replacing crossings with roundabouts has been shown to reduce the number of crashes with injuries or fatalities significantly (Elvik 2003). In driver education, novice motorists are familiarized with the effects of speed. In the Netherlands, a mandatory educational program for speed offenders is a possible penalty. Enforcement has also proven to be an effective measure against speeding. Stationary speed enforcement alone is estimated to have reduced the number of accidents by $17 \%$, and speed cameras are estimated to have led to a reduction of $39 \%$ in fatal accidents (Elvik and Vaa 2009). In addition, a series of effective enforcement measures have been applied in the past, such as trajectory control and undercover surveillance.

History, however, shows that the engineering category of measures in vehicle design is underused: Vehicle design is usually focused on making the vehicle faster instead of making speeding more difficult. For example, research from Sweden shows that the average top speed of all newly sold passenger vehicles in Sweden has increased significantly over the past decades, increasing from $153 \mathrm{~km} / \mathrm{h}$ in 1975 , to $172 \mathrm{~km} / \mathrm{h}$ in 1985 , to $194 \mathrm{~km} / \mathrm{h}$ in 1995 , and to over $200 \mathrm{~km} / \mathrm{h}$ in 2002 (Sprei et al. 2008). So, the trend in vehicle engineering is not so much to reduce the possibility of exceeding the speed limit, but to enable the driver to drive faster. In-vehicle systems that assist the driver in the task of driving the vehicle are called 'advanced driver assistance systems' (ADAS). An example of an ADAS that is designed to assist the driver in choosing the appropriate speed is 'intelligent speed adaptation' (ISA).

ISA is an in-vehicle system that helps the driver to comply with the legal speed limit at a certain location. ISA technology is relatively straightforward. It uses the functionality of systems that are already available in most vehicles (e.g., a GPS device, digital maps, and engine management systems). Most ISA devices can be assigned to one of three categories depending on how intervening (or permissive) they are (Carsten and Tate 2005):

- Advisory-Display the speed limit and remind the driver of changes in the speed limit. 
- Voluntary ("driver-select") —Allow the driver to enable and disable control by the vehicle of maximum speed.

- Mandatory-The vehicle is limited to travel at or below the speed limit at all times.

In addition to categorization by the level of intervention the system gives, ISA devices can be categorized by the type of speed limit information used:

- Fixed: The vehicle is informed of the posted speed limits.

- Variable: The vehicle is additionally informed of certain locations in the network where a lower speed limit is implemented. Examples could include around pedestrian crossings or the approach to sharp horizontal curves. With a variable system, the speed limits are current spatially.

- Dynamic: Additional lower speed limits are implemented because of network or weather conditions, to slow traffic in fog, on slippery roads, around major incidents, etc. With a dynamic system, speed limits are current temporarily.

Since the early 1980s, the effects of ISA have increasingly been studied using different methodologies and data collection techniques, including traffic simulation, driving simulators, and instrumented vehicles. ISA has also been demonstrated in different trials around the world (e.g., Sweden, the Netherlands, the UK, and Australia). The conclusions from all these trials and research are unambiguous regarding the positive effect of ISA on driving speed and the calculated effects on traffic safety. For instance, Carsten and Tate (2005) estimate that fitting all vehicles with a simple mandatory ISA system, making it impossible for vehicles to exceed the speed limit, would reduce injury accidents by $20 \%$ and fatal accidents by $37 \%$ (see Table 8.1 ). Adding a capability to respond to real-time network and weather conditions would result in a reduction of $36 \%$ in injury accidents and 59\% in fatal accidents. In general, it can be concluded that the more permissive the ISA, the less it affects speed choice behavior.

Other studies have confirmed that ISA can significantly reduce speeding and improve traffic safety (Lai et al. 2012). Although speeding is a major internationally recognized policy problem, and ISA seems a proven technology that has the potential to significantly contribute to traffic safety, the obvious question that remains is: Why is it that ISA has not yet been implemented except for some advisory systems? Part of the reason is related to the various (deep) uncertainties surrounding ISA implementation, including ISA technology development (in terms of reliability and accuracy to function properly under all circumstances), the way motorists will comply with ISA support, the impact of large-scale ISA penetration on congestion and travel times, the liability in case of ISA malfunctioning, and the preferences different stakeholders have regarding ISA implementation (van der Pas et al. 2012a).

So, policymakers are aware of the potential of ISA, but policymaking for ISA seems limited to supporting further research and development on ISA implementation. Policymakers are having trouble designing policies that deal appropriately with the uncertainties surrounding ISA implementation. 
Table 8.1 Best estimates of accident reductions by ISA type and severity

\begin{tabular}{l|l|l|l|l}
\hline System type & Speed limit type & $\begin{array}{l}\text { Best estimate of } \\
\text { injury accident } \\
\text { reduction (\%) }\end{array}$ & $\begin{array}{l}\text { Best estimate of } \\
\text { fatal and serious } \\
\text { accident } \\
\text { reduction }(\%)\end{array}$ & $\begin{array}{l}\text { Best estimate of } \\
\text { fatal accident } \\
\text { reduction (\%) }\end{array}$ \\
\hline \multirow{2}{*}{ Advisory } & Fixed & 10 & 14 & 18 \\
\cline { 2 - 5 } & Variable & 10 & 14 & 19 \\
\cline { 2 - 5 } & Dynamic & 13 & 18 & 24 \\
\hline \multirow{2}{*}{ Voluntary } & Fixed & 10 & 15 & 19 \\
\cline { 2 - 5 } & Variable & 11 & 16 & 20 \\
\cline { 2 - 5 } & Dynamic & 18 & 26 & 32 \\
\hline \multirow{2}{*}{ Mandatory } & Fixed & 20 & 29 & 37 \\
\cline { 2 - 5 } & Variable & 22 & 31 & 39 \\
\cline { 2 - 5 } & Dynamic & 36 & 48 & 59 \\
\hline
\end{tabular}

Source Carsten and Tate (2005)

\subsection{Reason for Choosing the DAP Approach}

There are many uncertainties that surround ISA implementation. Many of these are not Level 4 (deep) uncertainties (e.g., how the main mechanisms work is understood and the range of things that can go wrong is known). However, there is deep uncertainty about issues such as liability if the system fails, driver acceptance (willingness to use), the behavioral adaptation of ISA drivers and road users who do not have ISA, the effects of different implementation strategies, and the effects of a large-scale real-world implementation of ISA.

One way of obtaining insights into these uncertainties would have been to initiate pilot projects and monitor their results. But, our research was begun shortly after the literature on planning for adaptation to handle deep uncertainty had begun to appear (Walker et al. 2001; Lempert et al. 2003). It was clear that traditional approaches, designed for lower levels of uncertainty, were not entirely appropriate for the higher levels. Given the urgency of the road safety problem, and the availability of new approaches for dealing with deep uncertainty, we decided to get insights into the risks associated with the implementation of ISA by using experts to apply one of the approaches to designing a plan in the face of deep uncertainty-Dynamic Adaptive Planning.

\subsection{Methods for Applying DAP}

The design of dynamic adaptive plans requires a new and innovative way of using policy analysis methods. These methods are not only used to select an initial promis- 
ing plan; the methods are also used to probe for the vulnerabilities (and opportunities) of the initial plan and ways to protect it from failing (and to seize opportunities). Thus, decisionmakers can be prepared for the future and can be informed in advance when (under what conditions) and how their plan can be adapted. As described in Chap. 3, the process of designing a dynamic adaptive plan consists of five steps:

I. Setting the stage;

II. Assembling the initial plan;

III. Increasing the robustness of the initial plan;

IV. Setting up the monitoring system;

V. Preparing the contingent actions.

Below, we elaborate on methods that could be used to facilitate each step in practice.

In Step I and Step II, the activities carried out to determine an initial plan are essentially the same as those carried out in choosing a policy in a traditional policy analysis study (see Walker 2000). Step I is the stage-setting step. It involves the specification of objectives, constraints, and available policy alternatives. This specification should lead to a definition of success, in terms of the specification of desirable outcomes.

In Step II, a promising initial plan is identified based on a traditional, ex-ante evaluation of the alternatives identified in Step I. There are many well-established methods that can be used to screen the alternatives, including cost-benefit analysis (Sassone and Schaffer 1978), multi-criteria analysis (French et al. 2009), and balanced scorecards (Kaplan and Norton 1993), combined with the results from forecasts, scenarios, models, etc.

Step III focuses on (1) the identification and assessment of the vulnerabilities and opportunities of this initial plan and (2) the design of actions to increase the robustness of the initial plan. Five types of actions can be taken immediately upon implementation of the initial plan to address these vulnerabilities (and opportunities). These five types of actions (which are explained in more detail in Chap. 3) are:

- Mitigating actions (M) - Actions that reduce adverse impacts on a plan stemming from certain (or very likely) vulnerabilities;

- Hedging actions $(\mathrm{H})$ - Actions that reduce adverse impacts on a plan, or spread or reduce risks that stem from uncertain vulnerabilities (much like buying car insurance);

- Seizing actions (SZ) — Actions that take advantage of certain (or very likely) opportunities that may prove beneficial to the plan.

- Exploiting actions (E)_Actions that take advantage of (uncertain) new developments that can make the plan more successful, or succeed sooner;

- Shaping actions (SH)-Actions taken proactively to affect external events or conditions that could either reduce the plan's chance of failure or increase its chance of success.

There are a variety of tools and methods that can be used to identify the vulnerabilities and opportunities of an initial plan. They can be divided into two broad categories:

- Techniques that use (computational) models. Examples include sensitivity analysis (Saltelli et al. 2001), Scenario Discovery (SD) (Bryant and Lempert 2010), and 
Exploratory Modeling (EM) (Bankes 1993; Agusdinata 2008). These techniques can be used to identify vulnerabilities and opportunities by varying model inputs across the range of plausible parameter values (Kwakkel et al. 2012) or by exploring outcomes across alternative models of the system of interest (Bankes 1993; Agusdinata 2008).

- Techniques that support experts in the process of identifying assumptions, vulnerabilities, and opportunities. Several examples are included in Sect. 3.2. In this case, we used strengths, weaknesses, opportunities, and threats (SWOT) analysis (Osita et al. 2014), and threats, opportunities, weaknesses, and strengths (TOWS) analysis (Weihrich 1982).

Once the vulnerabilities and opportunities related to the initial plan are identified, these should be assessed in terms of their level of uncertainty (is the vulnerability certain or uncertain), in order specify the type of appropriate action (mitigating or hedging) to take. (If the uncertainty is certain or very likely, take it right away; if it is uncertain, make it a contingent action.) Typically, this 'uncertainty rating or ranking' is very subjective.

The second part in Step III (increasing robustness) requires that specific actions are specified. Dewar et al. (1993) mention five methods for identifying these actions (all of which can be used in a workshop setting): (a) using relevant theories of causation, (b) using historical and comparative experiences, (c) using creativity, (d) using scenarios, and (e) using insurance or regulatory requirements. However, their report does not show how to identify the appropriate actions in a structured and integrated way. SWOT analysis and TOWS analysis can be used to fill this gap. The SWOT analysis reveals the strengths, weaknesses, opportunities, and threats; TOWS then uses the SWOT analysis as input to identify suitable actions in light of the SWOT results.

In Step IV, a monitoring system is designed, and conditions suggesting that a change in the plan is needed (in order to save it from failure or increase the chances for its success) are specified (these are called 'triggers'). The monitoring system tracks the development of the uncertain vulnerabilities of the initial plan (the developments that are being tracked are called 'signposts'). Levels of the signposts beyond which the objectives of the plan will not be reached (the triggers, also known in the DMDU literature as adaptation tipping points) are predefined, and appropriate responsive actions are specified (these are designed in Step V). Several techniques can be used to design a monitoring system. Recently developed techniques that can be used for defining trigger values are based on Exploratory Modeling and Analysis (Agusdinata 2008), Scenario Discovery (Bryant and Lempert 2010), and a technique described by Botterhuis et al. (2010), which combines the detection of weak signals with scenarios.

Once the adaptive plan has been designed, the results from Steps I-IV are implemented and the contingent actions (Step V) are prepared. The implementation process is suspended until a trigger event occurs. 


\subsection{Setting up a DAP Workshop on ISA Implementation}

We operationalized the steps of DAP through means of a structured workshop, using a group decision room (GDR) to support the workshop process. The GDR is a group decision support tool that supports quick and efficient teamwork and the generation of information. In our GDR, the participants provided input using a laptop computer that was connected to a server. The (anonymous) results are directly visible to the participants, so participants are confronted with their own input and that of other participants. Also, there is the opportunity to react to each other's input or to add information. Because the information is anonymous, nobody can dominate the discussion. Figure 8.1 summarizes the workshop process (which is fully described in van der Pas (2011)). The relationship between this process and the DAP steps is the following:

\section{DAP Steps I and II: Setting the stage and assembling an initial plan}

Steps I and II used the actual ISA implementation strategy of the Dutch Ministry of Transport (as specified in interviews with policymakers and internal policy documents of the Ministry). This made it possible for the Dutch policymakers to use the generated information in their everyday jobs, and it allowed for an ex post assessment comparison (in a few years) of the actual plan with the adaptive plan that they had designed.

DAP Steps III, IV, and V: Increasing the robustness of the initial plan, setting up the monitoring system, and preparing the contingent actions

Steps III, IV, and V were supported through a combined SWOT-TOWS analysis, as follows:

i. List the various strengths, weaknesses, opportunities, and threats for the initial ISA implementation plan (structured brainstorm in the GDR). (Note: Both weaknesses and threats were considered to be vulnerabilities of the plan.)

ii. Identify a 'top 10' for each SWOT category (ranking using the GDR).

iii. Score the items in these top 10's on their uncertainty and importance for the outcomes of the initial plan (scoring items on a five-point scale).

iv. Define actions, signposts, and trigger values for the vulnerabilities and the opportunities for the high uncertain/high-impact items (TOWS uses the SWOT analysis as input and translates the outcomes of the SWOT into actions).

Figure 8.2 is the flowchart for vulnerabilities, which was developed to support these activities. (There was also a flowchart for opportunities. For reasons of space, only the flowchart for vulnerabilities is shown.) 


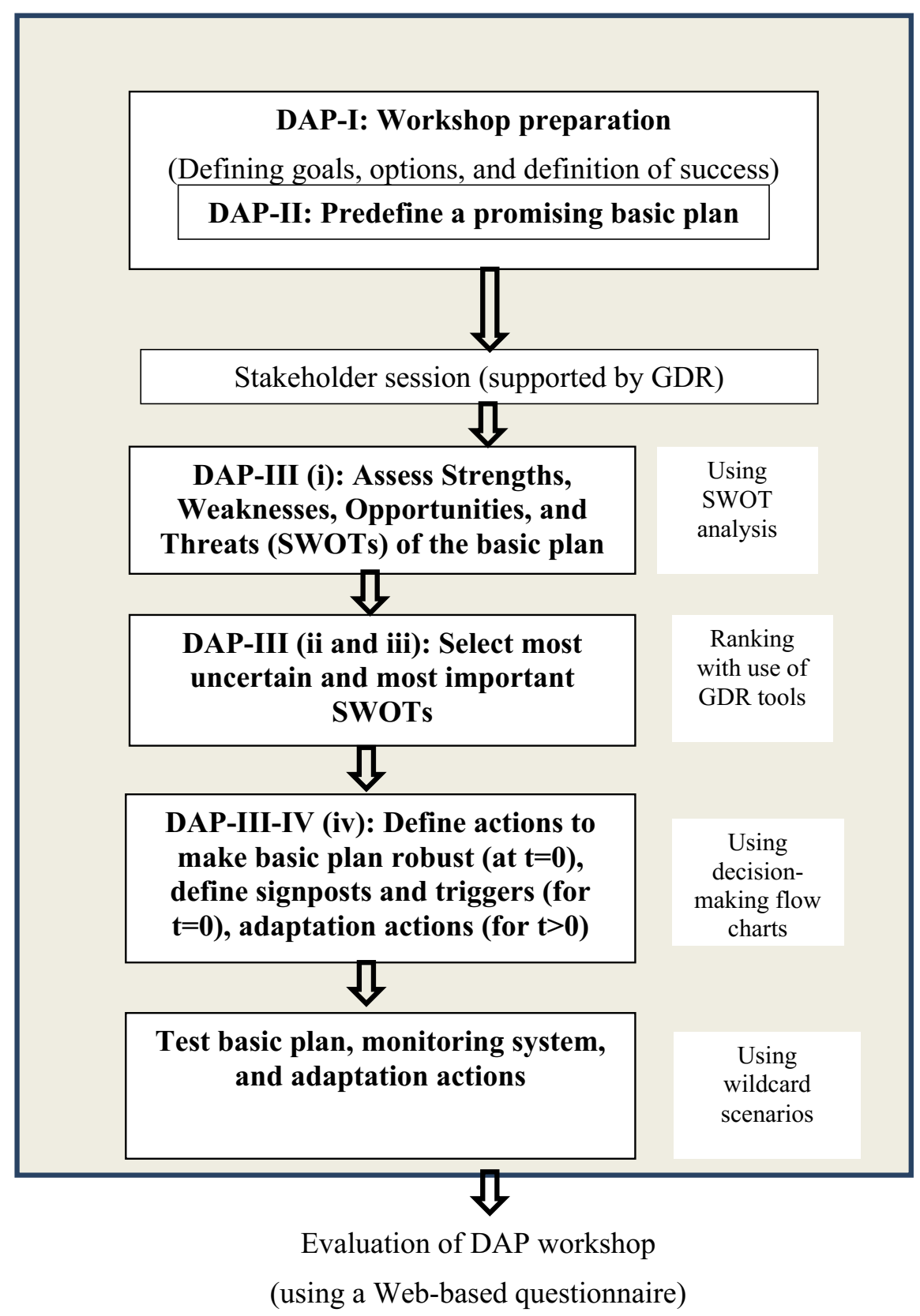

Fig. 8.1 Workshop process 


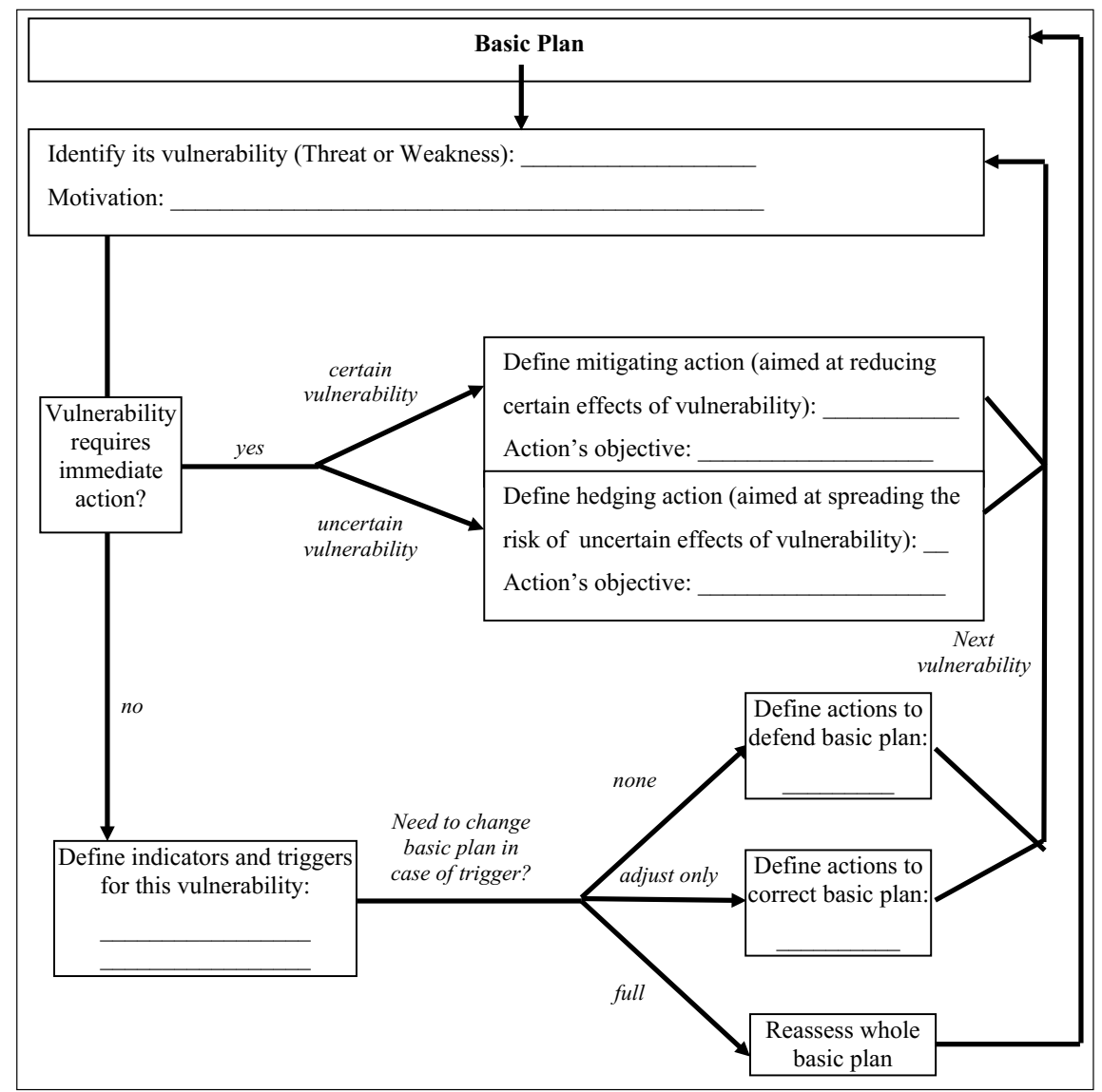

Fig. 8.2 Decisionmaking flowchart for identifying vulnerabilities and protective actions

\subsection{Results of the DAP-ISA Workshop}

The workshop was held in December 2010. For the workshop, we invited representatives of most of the important actors for ISA implementation in the Netherlands (Walta 2011), resulting in 18 participants. The participants included policymakers (4), scientists (7), consultants (5), an ISA system developer (1), and an insurance specialist (1). So, most of the important actors for ISA implementation were represented (at least one representative of each important group was included). Each of the respondents had over six years of work experience (the majority had over 10 years of experience). 


\section{Steps I and II: Setting the stage and assembling an initial plan}

An initial plan was presented to the participants. Table 8.2 presents an overview of the initial plan. The initial plan was formulated as follows: The Dutch Ministry of Transport wants to implement the most appropriate ISA for the most appropriate driver. Three types of vehicle drivers are distinguished:

- The compliant driver: This type of driver has the intrinsic motivation to stick to the speed limit. Their ISA would be only a speed alert. Implementation would primarily involve an education campaign.

- The less compliant driver: This type of driver lacks the intrinsic motivation to stick to the speed limit. They would get to choose the type of ISA to be used. Incentives would be offered by insurance and lease companies.

- The notorious speed offender: Under the current regime, this type of driver would lose his or her driver's license (and would be obliged to follow a traffic behavior course). In place of these draconian measures, they would be forced to use restricting ISA. A pilot test would be undertaken to provide information on how well the plan might be expected to work.

The implementation of ISA would consist of two phases. Phase I would run up to the end of 2012. In 2013, a still undefined Phase II would start. During the workshop, the participants were asked to reflect upon this initial plan.

Step III: Increasing the robustness of the basic plan

The participants identified several vulnerabilities and a few opportunities related to the initial ISA plan shown in Table 8.2. Some of these vulnerabilities and opportunities could be addressed at the time the plan was implemented-i.e., the initial plan could be made more robust. Table 8.3 presents an overview of these vulnerabilities and opportunities and the actions that could be taken to improve the robustness of the initial plan.

For example, 'the availability of an accurate speed limit database' was considered a certain high-impact weakness. Speed limit data must be correct for the right time (dynamic), the right location, and the right vehicle. The participants discussed whether they should deal with this vulnerability right away, or whether they could wait until a predefined situation occurs (i.e., a trigger event). They decided that it is important to immediately deal with this uncertainty (so they followed the arrow down in the decisionmaking flowchart in Fig. 8.2).

The availability of an up-to-date database was considered to be either a certain or uncertain vulnerability. The participants next discussed its uncertainty level and decided that while the effects of incorrect speed limit data are very uncertain, it is fairly certain that this vulnerability will occur. They therefore filled in the box at the bottom of Fig. 8.2 (indicating the need for mitigating actions).

Steps IV and V: Setting up the monitoring system and preparing the contingent actions

Using the same decisionmaking flowcharts shown in Fig. 8.2, the participants defined the signposts, triggers, and contingent actions. A subset of these is shown in Table 8.4. 


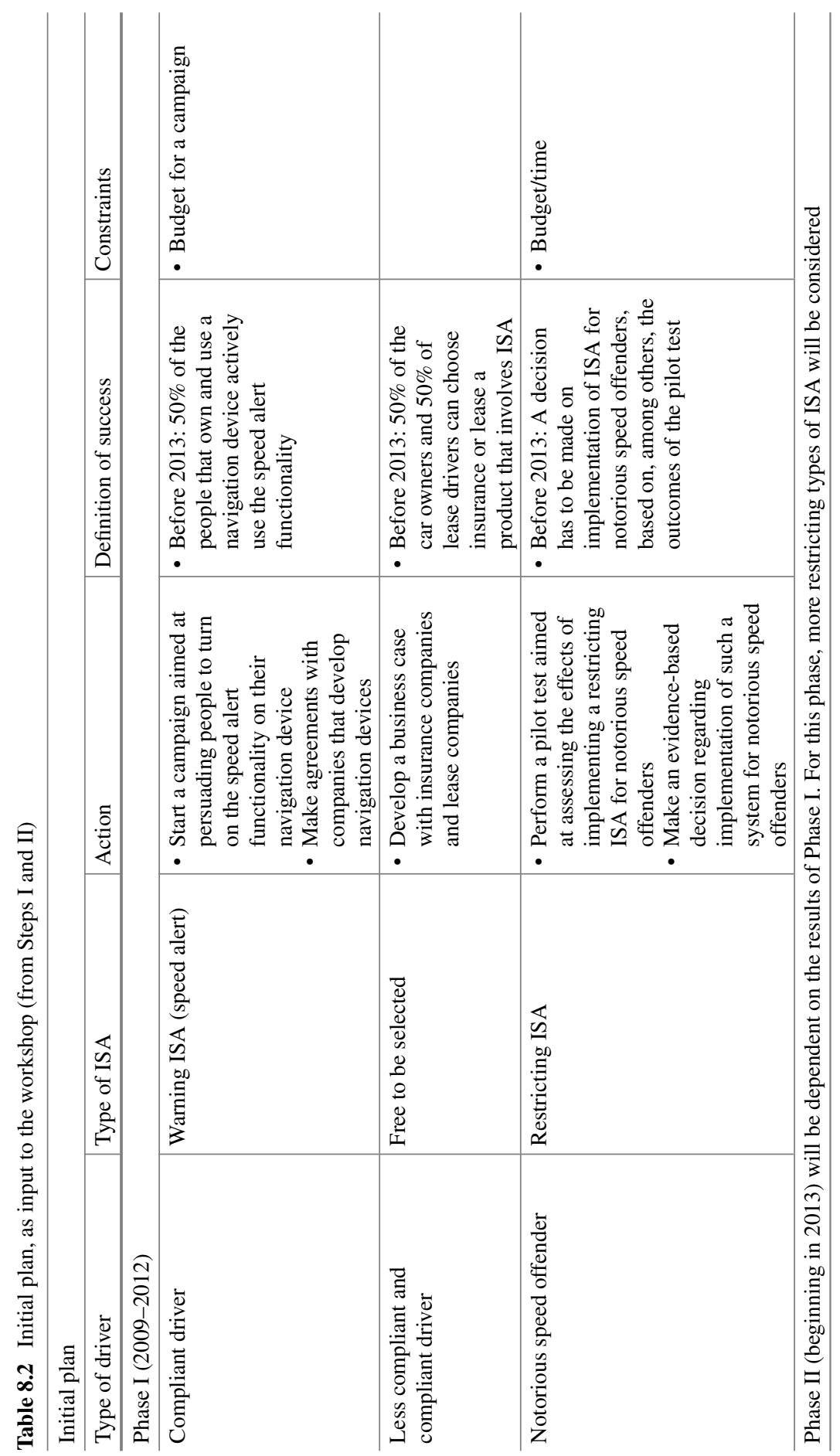


Table 8.3 Increasing the robustness of the initial plan

\begin{tabular}{|c|c|}
\hline Vulnerabilities (V) and Opportunities (O) & $\begin{array}{l}\text { Hedging }(\mathrm{H}) \text {, Mitigating }(\mathrm{M}) \text {, Seizing }(\mathrm{S}) \text {, } \\
\text { and Exploiting }(\mathrm{E}) \text { actions }\end{array}$ \\
\hline $\begin{array}{l}\text { V: Implementing a restricting ISA for } \\
\text { notorious speed offenders will damage the } \\
\text { image of the less intervening ISA systems. } \\
\text { ISA will be associated with punishment not } \\
\text { with assistance (as it is now) }\end{array}$ & $\begin{array}{l}\text { H: Decouple the pilot from the rest of the } \\
\text { initial plan, and avoid the term ISA } \\
\text { (currently done by calling it speed-lock) }\end{array}$ \\
\hline $\begin{array}{l}\text { V: The availability of an accurate speed limit } \\
\text { database. Speed limit data have to be } \\
\text { correct for right time (dynamic), the right } \\
\text { location, and the right vehicle }\end{array}$ & $\begin{array}{l}\text { This is a certain vulnerability, so: } \\
\text { M: Define and apportion responsibilities } \\
\text { before starting with implementation } \\
\text { M: Issue a request for bids for the } \\
\text { development of a speed limit database } \\
\text { (this should be arranged by public } \\
\text { authorities) } \\
\text { M: Guarantee quality through a third party } \\
\text { that is under the supervision of the } \\
\text { public authorities } \\
\text { M: Develop a system based on beacons that } \\
\text { overrule the static speed limit } \\
\text { information (failsafe design) }\end{array}$ \\
\hline $\begin{array}{l}\text { V: Automotive lobby will oppose the } \\
\text { large-scale implementation of ISA }\end{array}$ & $\begin{array}{l}\text { H: Include automobile manufacturers in the } \\
\text { implementation strategy }\end{array}$ \\
\hline $\begin{array}{l}\text { V: Speed limit data change more frequently } \\
\text { than expected (by time and location) }\end{array}$ & $\begin{array}{l}\text { H: Implement ISA systems that are robust } \\
\text { against this situation (i.e., systems that } \\
\text { allow for communication with the } \\
\text { infrastructure, to transmit temporary } \\
\text { speed limits-e.g., radio, Bluetooth) }\end{array}$ \\
\hline $\begin{array}{l}\text { O: Cars and ISA draw lots of attention and } \\
\text { appeal to people's emotions. Instead of } \\
\text { seeing this as a threat, this can be used as an } \\
\text { opportunity }\end{array}$ & $\begin{array}{l}\text { S: Invite stakeholders that have positive } \\
\text { feelings about ISA to participate in } \\
\text { improving and implementing ISA (e.g., } \\
\text { the presenters of Top Gear, race drivers) }\end{array}$ \\
\hline $\begin{array}{l}\text { O: People/companies are more willing to adopt } \\
\text { a technology if they can see the technology } \\
\text { in practice. Creating a pool of cars that are } \\
\text { equipped can result in an uptake of the } \\
\text { technology }\end{array}$ & $\begin{array}{l}\text { S: Practice what you preach. Let the } \\
\text { Ministry equip its fleet with ISA to set an } \\
\text { example. Prove that ISA can significantly } \\
\text { reduce the number of accidents and can } \\
\text { result in fewer insurance claims }\end{array}$ \\
\hline
\end{tabular}

Chapter 3 describes the four types of contingent (trigger event) actions that can be taken:

- Defensive actions (DA)-Responsive actions taken after initial implementation to clarify the plan, preserve its benefits, or meet outside challenges in response to specific triggers, but that leave the initial plan unchanged;

- Corrective actions (CR) — Adjustments to the plan in response to specific triggers;

- Capitalizing actions (CP)_Responsive actions taken after initial implementation to take advantage of opportunities that further improve the performance of the initial plan; 
Table 8.4 Monitoring system and contingent actions

\begin{tabular}{|c|c|c|}
\hline $\begin{array}{l}\text { Vulnerabilities (V) and } \\
\text { Opportunities (O) }\end{array}$ & $\begin{array}{l}\text { Monitoring and triggering } \\
\text { system }\end{array}$ & $\begin{array}{l}\text { Actions: Reassessment (R), } \\
\text { Corrective (CR), Defensive } \\
\text { (D), and Capitalizing (CP) }\end{array}$ \\
\hline $\begin{array}{l}\text { V: Implementing a restricting } \\
\text { ISA for notorious speed } \\
\text { offenders will damage the } \\
\text { image of the less obtrusive } \\
\text { ISA systems. ISA will be } \\
\text { associated with punishment } \\
\text { not with assistance (as it is } \\
\text { now) }\end{array}$ & $\begin{array}{l}\text { Monitor the: } \\
\text { - Number of negative press } \\
\text { publications } \\
\text { - Level of acceptance of } \\
\text { different ISA systems } \\
\text { - Number and type of } \\
\text { ISA-related questions } \\
\text { asked of politicians in the } \\
\text { lower house }\end{array}$ & $\begin{array}{l}\text { D: Media campaigns to } \\
\text { manage the perception } \\
\text { of people regarding ISA } \\
\text { (and the speed-lock); } \\
\text { explain the difference } \\
\text { and the need for } \\
\text { implementing such an } \\
\text { ISA for this type of } \\
\text { driver }\end{array}$ \\
\hline $\begin{array}{l}\text { V: The availability of an } \\
\text { accurate speed limit } \\
\text { database. Speed limit data } \\
\text { have to be correct for the } \\
\text { right time (dynamic), the } \\
\text { right location, and the right } \\
\text { vehicle }\end{array}$ & $\begin{array}{l}\text { Monitor the: } \\
\text { - Level of } \\
\text { accuracy/reliability of } \\
\text { speed limit database }\end{array}$ & $\begin{array}{l}\text { D: Initiate database } \\
\quad \text { accuracy enhancement } \\
\text { CR: Stop implementation of } \\
\text { certain types of ISA or } \\
\text { combine with on/off switch } \\
\text { and overruling possibilities } \\
\text { CR: Design the system in } \\
\text { such a way that it only } \\
\text { warns/intervenes in areas } \\
\text { with certain accuracy levels }\end{array}$ \\
\hline $\begin{array}{l}\text { V: Technology can fail: } \\
\text { - Location determination can be } \\
\text { inaccurate (e.g., in tunnels, in } \\
\text { cities with high buildings) } \\
\text { - Systems can stop functioning } \\
\text { (sensors fail, etc.) }\end{array}$ & $\begin{array}{l}\text { Monitor the: } \\
\text { - Cause of accidents } \\
\text { (relationship ISA-cause } \\
\text { of accident) } \\
\text { - Press releases on ISA and } \\
\text { accidents }\end{array}$ & $\begin{array}{l}\text { D: Make sure the market } \\
\text { improves the systems } \\
\text { (adjust implemented } \\
\text { rules and regulations } \\
\text { regarding system } \\
\text { functioning) } \\
\text { R: When large-scale failure } \\
\text { occurs or the effects are } \\
\text { drastic (ISA } \\
\text { implementation leads to } \\
\text { fatalities) }\end{array}$ \\
\hline $\begin{array}{l}\text { V: Speed limit data become } \\
\text { more and more dynamic }\end{array}$ & $\begin{array}{l}\text { Monitor the: } \\
\text { - Availability of dynamic } \\
\text { speed limits }\end{array}$ & $\begin{array}{l}\text { D: Make sure road } \\
\text { authorities equip new } \\
\text { dynamic speed limit } \\
\text { infrastructure with } \\
\text { infra-to-vehicle } \\
\text { communication (so } \\
\text { in-vehicle systems can } \\
\text { be easily adjusted) } \\
\text { D: Standardize } \\
\text { communication } \\
\text { protocols and } \\
\text { communication } \\
\text { standards }\end{array}$ \\
\hline
\end{tabular}


Table 8.4 (continued)

\begin{tabular}{|c|c|c|}
\hline $\begin{array}{l}\text { Vulnerabilities (V) and } \\
\text { Opportunities (O) }\end{array}$ & $\begin{array}{l}\text { Monitoring and triggering } \\
\text { system }\end{array}$ & $\begin{array}{l}\text { Actions: Reassessment (R), } \\
\text { Corrective (CR), Defensive } \\
\text { (D), and Capitalizing (CP) }\end{array}$ \\
\hline $\begin{array}{l}\text { O: ISA implementation can } \\
\text { result in larger cost savings } \\
\text { than expected, lower and } \\
\text { more homogeneous speeds, } \\
\text { lower consumption costs (fuel } \\
\text { savings + lower } \\
\text { maintenance), resulting in } \\
\text { higher levels of acceptance }\end{array}$ & $\begin{array}{l}\text { Monitor additional effects } \\
\text { of implementation on: } \\
\text { - Emissions } \\
\text { - Fuel use } \\
\text { - Throughput/congestion }\end{array}$ & $\begin{array}{l}\text { CP: Increase the number of } \\
\text { participating insurance } \\
\text { companies } \\
\text { CP: Use this information in } \\
\text { the business case for new } \\
\text { insurance and lease } \\
\text { companies }\end{array}$ \\
\hline
\end{tabular}

- Reassessment (RE) - A process initiated when the analysis and assumptions critical to the plan's success have lost validity (i.e., when unforeseen events cause a shift in the fundamental goals, objectives, and assumptions underlying the plan).

Table 8.4 shows the direct results from the workshop. Further operationalization of the signposts and related trigger values would be required to develop a monitoring system. For instance, consider the case of the second vulnerability mentioned: 'the availability of an accurate speed limit database.' The signpost suggested by the participants is: 'level of accuracy/reliability of speed limit database.' The next step would be to assign specific trigger values to the actions. For instance, if the accuracy of the speed limits in the database drops under a prespecified level of accuracy (e.g., 97\%), a defensive action should be triggered, and additional effort should be taken to make the speed limit database more accurate. If the accuracy drops below an even lower level (e.g., 60\%), a corrective action should be taken (i.e., the initial plan should be changed) as follows: 'Stop implementation of certain types of ISA or combine with on/off switch and overruling possibilities.' The specific trigger values would have to be determined (e.g., by using literature or additional modeling efforts).

After the dynamic adaptive plan was designed (as described above), the participants were asked to 'test' the extent to which they considered the designed plan to be 'future proof.' This process was supported by the use of wildcard scenarios (van Notten 2004). Examples of wildcard scenarios that were used are:

- After ISA is implemented, hackers develop ways to mislead the ISA systems, allowing people to speed without the system noticing.

- Current ISA systems use the USA satellite system to determine their position. The Americans 'play' with the accuracy of the system. In times of war, the system is more accurate than in times of peace and less accessible to civilians. In 2013, the USA is no longer at war and the accuracy is reduced. After 2013, the system becomes so inaccurate that safety issues arise.

The participants were asked to think about 'what if' the wildcard scenarios were to occur. In particular, they were asked to answer the following questions for each: 
- What would happen to the (road) transport system?

- What would happen to your adaptive plan, and how would the outcomes of the plan be influenced if this scenario were to occur?

- Is your adaptive plan capable of dealing with this scenario?

These wildcard scenarios led to interesting (and lengthy) discussions. A total of nine wildcard scenarios were assessed. In six cases, the groups indicated that their plan was capable of dealing with the wildcard scenario. Open questions asked of the participants in a follow-up questionnaire revealed that they appreciated the wildcard scenario portion of the workshop, and they stressed the added value of these scenarios.

\subsection{Evaluation of the DAP Approach}

In addition to the above assessment of workshop outcomes, we also used a (Webbased) questionnaire to elicit the participants' opinions on the DAP approach. The main results are displayed in Table 8.5.

As can be seen from the table, the participants were very positive about the suitability and usefulness of adaptive plans (\#1,2, and 5). They thought that the elements of the adaptive plan (actions, monitoring system, etc.) and the process of designing and implementing a plan would be useful for ISA implementation in the Netherlands $(\# 3,7)$ and that policymakers were capable of using the process (\#6). However, they agreed that the process of developing and implementing such a plan was more timeconsuming than that required for a traditional static plan (\#4). For an in-depth analysis of the results from the questionnaire, and an overview of the complete evaluation, see van der Pas et al. (2012b).

\subsection{Lessons Learned About the Process of Developing Dynamic Adaptive Plans}

By using a structured, participatory approach to developing a dynamic adaptive plan, we addressed the issues and challenges mentioned in Sect. 8.1. We used SWOT, TOWS, a group decision room, wildcard scenarios, decisionmaking flowcharts, etc. In addition, we tested this approach in a workshop with experts, stakeholders, and policymakers and evaluated it by canvassing the opinions of the workshop participants. We found that the workshop approach we used is promising and can produce a usable adaptive robust plan. However, we found that better ways are needed to identify the signposts and trigger values. This information could come from the use of other methods. A promising technique to do this might be Scenario Discovery (SD) (Bryant and Lempert 2010). Future applications of SD in the context of DAP can prove useful in identifying signposts and trigger values. Hermans et al. (2017) also provide some useful suggestions for designing monitoring arrangements. 
Table 8.5 Participants' evaluation of the DAP approach $(n=18)$

\begin{tabular}{|c|c|c|c|c|}
\hline \# & Workshop & $\begin{array}{l}\text { Median }^{\mathrm{a}} \\
\text { [interquartile range] }\end{array}$ & Max & Min \\
\hline 1 & $\begin{array}{l}\text { DAP is an appropriate way to develop a } \\
\text { plan for the implementation of ISA }\end{array}$ & $4[3-4.25]$ & 5 & 2 \\
\hline 2 & $\begin{array}{l}\text { ISA implementation using an adaptive } \\
\text { plan increases the chance of reaching the } \\
\text { ISA-related policy goals }\end{array}$ & $4[3.5-4]$ & 5 & 3 \\
\hline 3 & $\begin{array}{l}\text { The generated strengths, weaknesses, } \\
\text { opportunities, and threats, and the defined } \\
\text { actions, signposts, and trigger values can } \\
\text { be used in the ongoing effort of } \\
\text { developing ISA implementation plans for } \\
\text { the Netherlands }\end{array}$ & $4[4-5]$ & 4 & 3 \\
\hline 4 & $\begin{array}{l}\text { Developing and implementing adaptive } \\
\text { plans are more time-consuming than } \\
\text { developing and implementing traditional } \\
\text { static plans for ISA implementation }\end{array}$ & $3[2-4]$ & 5 & 1 \\
\hline 5 & $\begin{array}{l}\text { The expected benefits of developing } \\
\text { adaptive plans are bigger than the } \\
\text { expected costs (for problems that are } \\
\text { surrounded with deep uncertainty) }\end{array}$ & $4[3-4]$ & 5 & 2 \\
\hline 6 & $\begin{array}{l}\text { Policymakers in general are capable of } \\
\text { identifying the strengths, weaknesses, } \\
\text { opportunities, and threats, and to think of } \\
\text { actions to counter the weaknesses and } \\
\text { threats and profit from the strengths and } \\
\text { opportunities }\end{array}$ & $4[2-4]$ & 5 & 2 \\
\hline 7 & $\begin{array}{l}\text { Designing and implementing adaptive } \\
\text { plans fits the current practice of } \\
\text { policymaking in the Netherlands }\end{array}$ & $3[3-4]$ & 5 & 2 \\
\hline
\end{tabular}

${ }^{\mathrm{a}} 1=$ strongly disagree, $2=$ disagree, $3=$ neither disagree, nor agree, $4=$ agree, $5=$ strongly agree

Several further lessons were learned from the workshop and subsequent feedback. First, some decisions need to be taken before starting to design an adaptive plan. These are often related to the political process (e.g., the decision to use an analytical approach) and to educating the policymakers (e.g., the design of an adaptive plan might be costly and time-consuming, and the concepts are new). During the workshop, the experts had trouble dealing with these issues. This problem can be prevented by increasing the involvement of the participants over time. Instead of one workshop plus assessment and questionnaire, a dedicated task force could be formed with the responsibility to formulate an advice to the decisionmakers. The major stakeholders would be represented in the task force. The task force would meet 3 times. The first meeting would focus on making an inventory of the level of knowledge and the questions the members have. The second meeting would be 
a workshop in which the largest knowledge gaps and questions are dealt with. The third meeting would be to design the adaptive plan.

Second, the participants indicated that a vulnerability or opportunity is often neither $100 \%$ certain or uncertain. Although implicit in the DAP framework, it is not necessarily true in practice. An action can be assessed to be both fairly certain in some respects and uncertain in others. Consider, for instance, the vulnerability 'the ISA technology can fail; location determination can be inaccurate.' It is fairly certain that this will occur. However, one stakeholder judged this as uncertain, because the magnitude of the effects if it occurs is uncertain. So, one might want to define both a mitigating action (e.g., provide a warning to the driver when the system fails) and a reassessment action (in case fatalities with the system occur). Distinguishing between the uncertainty of occurrence and the uncertainty of impact when it occurs is an important distinction that should be made when developing adaptive plans.

Third, after the assessment of vulnerabilities and opportunities, a choice can be made whether to handle a specific vulnerability or opportunity through actions to be taken immediately or in the future in response to a trigger event. An assessment of the costs of both approaches is required to make a reasoned choice. No clear guidance on how to choose between taking immediate action or preparing for the future currently exists. Related to this, it proved to be impossible to specify trigger values during the workshop. This was not due only to practical time constraints, but also because defining trigger values involves very specific expertise and knowledge. A possible solution to this problem could be to introduce a fast simple transport model (FSM) into the workshop. This would allow for running simulations during the workshop in order to determine trigger values (FSMs are used in SD and EM). This solution was prototyped in a project related to the Colorado River, which was documented by Groves et al. (2016). They did this by reconvening a panel of experts at Lawrence Livermore Laboratory and going once more through the deliberative process, this time with the underlying exploratory models being operated and producing the required analyses in real time.

Fourth, although the initial plan distinguished three types of motorists (compliant, less compliant, and notorious speeders), the analysis showed that the vulnerabilities and opportunities mostly address either the notorious speeders or the overall initial plan (without distinguishing among the other types of motorists). This indicates that experts may find it difficult to assess a plan that consists of multiple alternatives (they might not address each alternative consistently). In the workshop, we had the impression that the experts focused on the underlying assumptions and tried to find vulnerabilities and opportunities for these (e.g., ISA should be a reliable technology, and for a GPS-based ISA, an accurate speed limit database is required). As a result, they came up with more generic vulnerabilities. Later, these would have to be translated into specific vulnerabilities for each of the alternatives for each of the target groups for which the plan is to be applied. 


\subsection{Conclusions}

Previous literature suggested that, conceptually, DAP is a promising policy design approach that is able to handle deep uncertainties. However, it also pointed out some major remaining challenges. Three of these challenges were addressed in this case. First, DAP lacked examples of adaptive plans developed by policymakers or domain experts. By designing an adaptive plan with policymakers, domain experts, and other stakeholders, we showed that policymakers are capable of designing dynamic adaptive plans. Second, DAP lacked well worked out examples of real-world policy problems. By using DAP to design an actual ISA implementation plan with policymakers, domain experts, and other stakeholders, we showed it can be used to address a real-world policy problem. In addition, the experts indicated that the plan could be used to encourage and speed up real-world implementation of ISA in the Netherlands. Third, DAP was previously a high-level concept, captured only in a flowchart, yielding only limited insight into its operationalization. By designing, applying, and evaluating a workshop, we showed how DAP can be operationalized by integrating existing research methods into an integrated design approach. Moreover, the process revealed problems that can be expected in doing so.

This case showed that the workshop approach is a promising way to design a robust, adaptive plan in the face of deep uncertainty. However, it also showed that there are still some issues that need to be addressed in future research in order to design an adaptive plan using DAP:

- The framework seems to be ambiguous regarding the moment of implementation. In particular, the participants had trouble defining when some of the actions should take place. (For example, certain required actions had to be taken before the adaptive plan could even begin to be implemented. These mainly related to the political process and to the perceived time and cost involved in designing and implementing a plan using DAP).

- Participants had trouble dealing with the fact that a vulnerability or opportunity is not either certain or uncertain (which influences the type of action that needs to be defined). There is a scale between certain and uncertain, so an action can be assessed by participants to be both fairly certain in some respects and uncertain in others. In addition, although DAP is selected because the decision problem at hand is considered deeply uncertain, this does not mean that every aspect of the decision problem is uncertain. It is important for the participants to have a clear picture of which dimension of deep uncertainty is being addressed. In terms of the definition given by Lempert et al. (2006), we distinguished three dimensions: deep uncertainty regarding the appropriate model, (2) deep uncertainty regarding the prior probability distributions for inputs to the model and their interdependencies, and (3) deep uncertainty regarding the stakeholder preferences that can be used to rank policy alternatives. Participants need to have a clear picture of what aspect of these dimensions is being addressed by each of the vulnerabilities and opportunities. Methods to indicate the dimensions of deep uncertainty could be useful here. 
- For each of the vulnerabilities and opportunities, a choice can be made whether to handle these through actions to be taken immediately (an initial action) or in the future in response to a trigger event (a contingent action). Participants struggled to find criteria that could be used to resolve the timing of the actions.

- Experts had trouble dealing with the fact that the initial plan was a package of actions. Going through the process of defining vulnerabilities and opportunities, signposts and trigger values, and contingent actions for each of the actions in the initial plan proved a challenge. As a result, they did not address each of these actions consistently. This is likely due to the setup of the workshop. Future workshops should include mechanisms to deal with policy packages more effectively.

All of these issues should be addressed in work aimed at improving the DAP approach.

With regard to ISA, the work confirmed the hypothesis that DAP is a useful approach for dealing with the uncertainties related to its implementation. Traditional/current ISA policies involve either 'do nothing' (no ISA) or 'do the wrong thing' (e.g., ISA for everybody). DAP enables policymakers to begin implementation, to monitor developments, and to adjust the plan based on real-world developments that cannot be predicted.

\section{References}

Agusdinata, D. B. (2008). Exploratory Modeling and Analysis to Deal with Deep Uncertainty. Ph.D. Thesis, Delft University of Technology, Delft.

Bankes, S. (1993). Exploratory modeling for policy analysis. Operations Research, 4(3), 435-449.

Botterhuis, L., van der Duin, P., de Ruijter, P., \& van Wijck, P. (2010). Monitoring the future: Building an early warning system for the Dutch ministry of justice. Futures, 42(5), 454-465.

Bryant, B. P., \& Lempert, R. J. (2010). Thinking inside the box: A participatory, computer-assisted approach to scenario discovery. Technological Forecasting and Social Change, 77(1), 34-49.

Carsten, O. M. J., \& Tate, F. N. (2005). Intelligent speed adaptation: Accident savings and costbenefit analysis. Accident Analysis and Prevention, 37(3), 407-416.

Dewar, J. A., Builder, C. H., Hix, W. M., \& Levin, M. (1993). Assumption-based planning: A planning tool for very uncertain times. Santa Monica, CA: MR114-A, RAND.

Elvik, R. (2003). Effects on road safety of converting intersections to roundabouts: Review of evidence from non-U.S. studies. Transportation Research Record: Journal of the Transportation Research Board, 1847, 1-10.

Elvik, R., \& Vaa, T. (2009). The handbook of road safety measures (2nd ed.). Oxford: Elsevier Ltd.

French, S., Maule, J., \& Papamichail, N. (2009). Decision behaviour analysis and support. Cambridge (UK): Cambridge University Press.

Groves, D. G., R. J. Lempert, D. W. May, J. R. Leek, and J. Syme (2016). Using high-performance computing to support water resource planning: A workshop demonstration of real-time analytic facilitation for the Colorado River Basin, RAND Corporation and Lawrence Livermore National Laboratory, CF-339-RC, 2016. Retrieved December 30, 2017 from https://www.rand.org/pubs/ conf_proceedings/CF339.html.

Hermans, L. M., Haasnoot, M., ter Maat, J., \& Kwakkel, J. H. (2017). Designing monitoring arrangements for collaborative learning about adaptation pathways. Environmental Science \& Policy, 69, 29-38. 
Kaplan, R. S., \& Norton, D. P. (1993). Putting the balanced scorecard to work. Harvard Business Review, 71(5), 134-147.

Kwakkel, J. H. (2010). The treatment of uncertainty in airport strategic planning. Ph.D. Thesis, Delft University of Technology, Delft.

Kwakkel, J. H., Walker, W. E., \& Marchau, V. A. W. J. (2012). Assessing the efficacy of adaptive airport strategic planning: Results from computational experiments. Environment and Planning B: Planning and Design, 39, 533-550.

Lai, F., Carsten, O., \& Tate, F. (2012). How much benefit does intelligent speed adaptation deliver: An analysis of its potential contribution to safety and environment. Accident Analysis and Prevention, 48, 63-72.

Lempert, R. J., Popper, S. W., \& Bankes, S. C. (2003). Shaping the next one hundred years: New methods for quantitative long-term policy analysis. Santa Monica: RAND.

Lempert, R. J., Groves, J. D. G., Popper, S. W., \& Bankes, S. C. (2006). A general, analytic method for generating robust strategies and narrative scenarios. Management Science, 52(4), 514-528.

OECD-Organization for Economic Co-Operation and Development (2006). Speed Management. Paris: OECD.

Oei, H. L. (2001). Safety Consequences of Intelligent Speed Adaptation (ISA). Report R-2001-11. Institute for Road Safety Research (SWOV), Leidschendam.

Osita, H. C., Idoko O. R., \& Nzwkwe, J. (2014). Organization's stability and productivity: The role of SWOT analysis. International Journal of Innovative and Applied Research, 2(9), 23-32.

Saltelli, A., Chan, K., \& Scott, E. M. (2001). Sensitivity analysis. New York: Wiley.

Sassone, P. G., \& Shaffer, W. A. (1978). Cost-benefit analysis-A handbook. San Diego: Academic Press.

Sprei, F., Karlsson, S., \& Holmberg, J. (2008). Better performance or lower fuel consumption: Technological development in the Swedish new car fleet 1975-2002. Transportation Research Part D, 13(2), 75-85.

Swanson, D., Barg, S., Tyler, S., Venema, H., Tomar, S., \& Bahdwal, S. (2010). Seven tools for creating adaptive policies. Technological Forecasting and Social Change, 77(6), 924-939.

van der Pas, J. W. G. M. (2011). Clearing the road for ISA implementation? applying adaptive policymaking for the implementation of intelligent speed adaptation. Delft, the Netherlands: TRAIL Thesis Series, T2011/13.

van der Pas, J. W. G. M., Marchau, V. A. W. J., Walker, W. E., van Wee, G. P., \& Vlassenroot, S. H. (2012a). ISA implementation and uncertainty: A literature review and expert elicitation study. Accident Analysis and Prevention, 48, 83-96.

van der Pas, J. W. G. M., Kwakkel, J. H., \& van Wee, B. (2012b). Evaluating adaptive policymaking using expert opinions. Technological Forecasting and Social Change, 79, 311-325.

van Notten, P. (2004). Writing on the wall: Scenario development in times of discontinuity. Ph.D. thesis, University of Maastricht, Maastricht.

Walker, W. E. (2000). Policy analysis: A systematic approach to supporting policymaking in the public sector. Journal of Multicriteria Decision Analysis, 9(1-3), 11-27.

Walker, W. E., Rahman, S. A., \& Cave, J. (2001). Adaptive policies, policy analysis, and policymaking. European Journal of Operational Research, 128, 282-289.

Walta, L. (2011). Getting ADAS on the Road-Actors' interactions in advanced driver assistance systems deployment. Ph.D. Thesis, Delft University of Technology, Delft.

Weihrich, H. (1982). The TOWS matrix: A tool for situational analysis. Long Range Planning, $15(2), 54-66$.

WHO-World Health Organization. (2015). Global status report on road safety 2015. Geneva: WHO Press.

Prof. Vincent A. W. J. Marchau (Radboud University (RU), Nijmegen School of Management) holds a chair on Uncertainty and Adaptivity of Societal Systems. This chair is supported by The 
Netherlands Study Centre for Technology Trends (STT). His research focuses on long-term planning under uncertainty in transportation, logistics, spatial planning, energy, water, and security. Marchau is also Managing Director of the Dutch Research School for Transport, Infrastructure and Logistics (TRAIL) at Delft University of Technology (DUT), with 100 Ph.D. students and 50 staff members across 6 Dutch universities.

Prof. Warren E. Walker (Emeritus Professor of Policy Analysis, Delft University of Technology). He has a Ph.D. in Operations Research from Cornell University, and more than 40 years of experience as an analyst and project leader at the RAND Corporation, applying quantitative analysis to public policy problems. His recent research has focused on methods for dealing with deep uncertainty in making public policies (especially with respect to climate change), improving the freight transport system in the Netherlands, and the design of decision support systems for airport strategic planning. He is the recipient of the 1997 President's Award from the Institute for Operations Research and the Management Sciences (INFORMS) for his 'contributions to the welfare of society through quantitative analysis of governmental policy problems.'

Dr. Jan-Willem G. M. van der Pas ( Eindhoven municipality) has a Ph.D. from Delft University of Technology. His research focused on policymaking under deep uncertainty for Intelligent Transport Systems. After receiving his Ph.D., he worked, respectively, as a researcher at the Delft University of Technology and as team manager, Smart Mobility, for a research and consultancy firm (DTV Consultants). Currently, Jan-Willem works as a strategist/coordinator, Smart Mobility, at Eindhoven municipality where he continues to improve the theory and practice of Dynamic Adaptive Planning.

Open Access This chapter is licensed under the terms of the Creative Commons Attribution 4.0 International License (http://creativecommons.org/licenses/by/4.0/), which permits use, sharing, adaptation, distribution and reproduction in any medium or format, as long as you give appropriate credit to the original author(s) and the source, provide a link to the Creative Commons licence and indicate if changes were made.

The images or other third party material in this chapter are included in the chapter's Creative Commons licence, unless indicated otherwise in a credit line to the material. If material is not included in the chapter's Creative Commons licence and your intended use is not permitted by statutory regulation or exceeds the permitted use, you will need to obtain permission directly from the copyright holder.

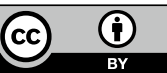

